\title{
Enlisting New Teachers in Clinical Environments (ENTICE); novel ways to engage clinicians
}

This article was published in the following Dove Press journal:

Advances in Medical Education and Practice

4 October 2014

Number of times this article has been viewed

\author{
Bruce Peyser ${ }^{1}$ \\ Kathryn A Daily² \\ Nicholas M Hudak ${ }^{3}$ \\ Kenyon Railey ${ }^{3}$ \\ Hayden B Bosworth ${ }^{1,4}$ \\ 'Department of Medicine, Division \\ of General Internal Medicine, \\ Duke University Medical Center, \\ Durham, NC, USA; ${ }^{2}$ Duke University \\ Medical Center, Durham, NC, USA; \\ ${ }^{3}$ Department of Community and \\ Family Medicine, Physician Assistant \\ Program, Duke University, Durham, \\ NC, USA; ${ }^{4}$ Center for Health Services \\ Research in Primary Care, Durham \\ Veterans Affairs Medical Center, \\ Durham, NC, USA
}

Purpose: To explore the barriers and incentives that affect primary care providers who precept students in outpatient clinics in the US.

Method: In 2013, leadership of our large primary care group sent a 20-question survey via e-mail to all of the 180 providers within the network. The survey assessed provider demographics, precepting history, learner preferences, and other issues that might affect future decisions about teaching.

Results: The response rate was 50\% (90 providers). The top reasons for precepting in the past were enjoyment for teaching and personal interaction with learners. The most commonly cited reason for not precepting previously was a perceived lack of time followed by increased productivity demands. When questioned about the future, $65 \%$ (59 respondents) indicated that they were likely to precept within the next 6 months. A desired reduction in productivity expectations was the most commonly cited motivator, followed by anticipated monetary compensation and adjusted appointment times. A top barrier to future precepting was a belief that teaching decreases productivity and requires large amounts of time.

Conclusion: This survey represents an opportunity to study a change in focus for a cohort of busy clinicians who were mostly new to teaching but not new to clinical practice. The survey provides further insight into clinician educators' perceptions regarding the education of a variety of different learners. The results align with data from previous studies in that time pressures and productivity demands transcend specific programs and learner backgrounds. This information is critical for future clerkship directors and hospital administrators in order to understand how to increase support for potential preceptors in medical education.

Keywords: clinical teaching, medical education, preceptors, primary care

\section{Background}

Anticipated health care work force shortages worldwide have prompted many institutions to expand their health professions, educational programs and enrollment. Part of this expansion has been driven by the anticipated need for an increased number of primary care providers due to changes in population growth and aging. ${ }^{1}$ Coincident with this expansion of programs has been increased demand for sites of instruction outside of the traditional hospital setting. Rotations for medical students are being shifted to the outpatient clinic, and longitudinal programs are demonstrating effectiveness with this model of instruction with improved levels of feedback, mentoring, and overall student satisfaction. ${ }^{2}$

The physician assistant and nurse practitioner professions were concurrently created to address the needs of an expanding patient population and decreased
Correspondence: Bruce Peyser General Internal Medicine, Duke University Medical Center, Box 3240

Med Ctr, Durham, NC, USA

$\mathrm{Tel}+\mathrm{I} 9194909800$

Fax + I 9199705304

Email bruce.peyser@duke.edu 
health care access. Although the specifics of the preclinical education process might differ depending upon the institution, real world experience through clinical rotations is a very necessary component of their medical education. Hence, demand for physician assistant and nurse practitioner education has increased, ${ }^{3-6}$ and many of these programs are also relying more heavily on clinical rotations and learning in the office-based setting.

This confluence of factors has led to insufficient numbers of training sites and preceptors. Finding sufficient numbers of teachers who are willing and capable of effectively overseeing learners within the field of outpatient primary care is a longstanding challenge. ${ }^{7,8}$ Additionally, curriculum changes, coupled with renewed interest in the field of primary care, have led to greater demands for longer periods of clinical instruction for more learners within the outpatient setting.

While there has been increased national demand for more outpatient clinician educators, there have been ongoing budgetary constraints within the field of internal medicine, leading to renewed emphasis within clinical programs on revenue generation and visit-volume levels. Productivity demands, compliance concerns, space constraints, and patient expectations are hypothesized to cause many office-based clinicians to avoid teaching commitments, but the available literature documenting such concerns is sparse. A thorough review of outpatient teaching was summarized by Alguire et al in their book entitled Teaching in Your Office, but the specific reasons why providers might not adopt learners in their office were only partially addressed. ${ }^{9}$ More recent literature relating to primary care physician satisfaction has focused more upon other issues such as those relating to the inordinate amounts of time necessary to coordinate care for complex patients. ${ }^{10}$

\section{Introduction}

As educators continue to grapple with increasing demands for primary care, consideration of how clinicians ensure appropriate and adequate training of new learners is crucial. Two years ago, our primary care network found itself presented with a unique opportunity. Our leadership team overseeing our large primary care practice made a decision to alter the focus and emphasis of our group's mission. Previously, clinicians in this group had been primarily involved with the provision of outpatient primary clinical care. However, recently, with the growing need of outpatient instructors at our institution, our mission was modified, and a teaching component was added. To this end, our group undertook a study to understand some of the incentives and barriers to precepting students among our primary care providers. Most of these students came from the Duke University School of Medicine's doctor of medicine and physician assistant programs, as well as from the nurse practitioner program at the Duke University School of Nursing.

This study was entitled ENTICE to emphasize the need to better understand ways to Enlist New Teachers In Clinical Environments. The results from our investigation are anticipated to help guide our own institutional policies and guidelines as we work to recruit and retain more preceptors for our many health professional students.

A review of the literature relating to barriers and motivators for primary care providers to teach revealed very few studies that collectively involved the instruction of medical students, physician assistant students, and nurse practitioner students. The majority of the articles reviewed focused on the mentoring relationship with students and the impact precepting had within the same discipline such as with a licensed physician assistant acting as a preceptor for a physician assistant student, or a nurse practitioner who precepted a nurse practitioner student. ${ }^{11,12}$ A limited number of studies have examined the barriers and the motivators for providing clinical mentoring within nursing schools. ${ }^{13}$ In 2011, a large national survey of physician assistants examined the characteristics of preceptors as well as incentives and barriers to precepting. The "lack of support from administrators" was detailed as a distinctive barrier to precepting more students. ${ }^{14}$ However, no large sample studies were found that examined concerns and issues faced amongst primary care providers acting as new preceptors for a spectrum of advanced practice students.

Thus, we set out to explore some of the barriers and incentives facing busy clinicians who were essentially being asked to transform themselves to become at least part-time clinician educators with learners of varied backgrounds and training. The following questions were explored: What currently motivates busy clinician educators to begin to teach? What incentives exist to induce these teachers to work with learners? Are these inducements sufficient, and/or effective? Finally, what work constraints ought to be addressed as they pertain to clinical teaching in the outpatient setting?

Understanding the motivations for why individuals elect to teach or not to teach could allow for adjustment of work expectations. Realization of provider concerns may also allow for other accommodations that could induce faculty to decide to teach in the outpatient setting, which is a goal that is felt to be an essential activity if we are to meet growing primary care needs in the near future. 


\section{Methods}

\section{Participants}

To gain further understanding of the barriers and incentives among primary care providers, we conducted an online survey of providers within the Duke Primary Care network, which in the spring of 2013, comprised 33 clinical sites and included practitioners of Primary Care Pediatrics, Internal Medicine, and Family Medicine in addition to five Urgent Care clinics. Providers within this network include physicians (Doctors of Medicine and Doctors of Osteopathy), Nurse Practitioners, and Physician Assistants. The Duke University Health System Institutional Review Board (IRB) approved this study in May 2013.

\section{The survey}

The survey was available via e-mail link for 26 days, in the spring of 2013. An initial e-mail request to complete the survey was sent to providers by the Chief Medical Officer of Duke Primary Care within the first week of the survey time period. Reminder e-mails to complete the survey were sent electronically within several weeks of the initial mailing.

The ENTICE survey contained 20 questions (Figure 1). Major demographic characteristics measured were age, ethnicity, sex, professional degree, primary area of practice, and years of practice. If providers had precepted in the past 6 months, data on years of precepting, frequency of precepting, and total number of learners precepted were obtained. Provider precepting preferences, such as type of learner (eg, medical student, resident, nurse practitioner student, or physician assistant student), anticipated likelihood of continuing to precept, ideal total months of precepting yearly, and recommendations relating to a precepting requirement and further training were also assessed. Participants were also asked to rank their top five reasons for wanting to start or continue precepting. Alternatively, those who did not wish to precept were queried as to their reasoning. Participants were able to provide individual comments after each question as well, though those comments are not included in this report.

\section{Results}

\section{Preceptor demographics}

A total of 90 fully completed surveys were received, yielding a response rate of $50 \%$; at least one provider at all practice sites completed the survey. Seventy percent $(n=63)$ of the respondents were experienced clinicians defined as having practiced in their field of specialty for at least 5 years, with $37 \%(n=33)$ of respondents practicing for 15 years or more. Over $35 \%(n=32)$ of the providers were older than 50 years old. Seventy-one percent $(n=64)$ of the respondents described themselves as Caucasian. The respondents were mostly female $(\mathrm{n}=52,57 \%)$. Respondents were mostly physicians ( $\mathrm{n}=66,73 \%) ; 14$ physician assistants and 8 nurse practitioners responded as well (about half of the total number in the organization). Almost $60 \%(n=52)$ of the physician respondents were family practitioners, over $22 \%(n=20)$ were internists, over $15 \%(n=14)$ were urgent care providers, and over $4 \%(n=4)$ were pediatricians (Table 1).

Despite many years of clinical practice, a majority of the providers were new to teaching; $56 \%(n=50)$ had served as a preceptor for less than 5 years and $13 \%(n=12)$ of the respondents had never taught in the outpatient setting before. Of those that had taught, most had started within the past 24 months $(n=62,69 \%)$. While the vast majority of the past and present learners were enrolled in clinical programs at Duke University, a small number $(n=7,8 \%)$ came from other institutions mostly within the region, though some enrolled from institutions as far away as Tennessee and Pennsylvania.

Half of the members of the primary care group elected not to respond to the survey. This group was comparable in makeup to the group that responded, with comparable gender breakdown ( $60 \%$ of the nonresponders were female). Forty-nine percent of the physicians failed to respond, $45 \%$ of the supervising physician assistants did not respond, while $67 \%$ of the nurse practitioners were nonresponders.

\section{Learner preferences}

When asked about learner preference, $71 \%(n=64)$ of the respondents indicated that they did not prefer a particular type of learner. Among the 21 physicians indicating a preference, 10 respondents specified that they preferred medical students or residents. Several providers commented that they preferred motivated learners, and a few stated that they preferred to teach learners committed to a particular field or specialty (eg, pediatrics, urgent care).

\section{Reasons for teaching}

Providers who had experience precepting reported that they enjoyed teaching, liked the personal interaction with learners, and wanted to help students learn (Table 2). A number of providers also indicated that they precepted because they were required to do so. The third and fourth most commonly cited reasons for teaching, respectively, were the opportunity to learn from the students and that 
the preceptor was committed to the future of his/her specialty.

\section{Barriers to teaching}

Conversely, the two most commonly cited reasons for not precepting over the preceding 2 years was a perceived lack of time followed by increased work productivity demands (Table 3). The third most frequent reason given was a perceived lack of opportunity to teach. The fourth reason was the concept that the current reimbursement model does not incentivize clinicians to teach in their practice. Lack of departmental recognition for teaching, lack of physical

\section{Duke}

Thank you for taking the time to complete the Duke Primary Care Survey about your involvement in clinical teaching.

Your feedback is important for us to better understand your willingness to precept interns, residents, nurse practitioners, physician assistants, and medical students.

The survey should only take five minutes of your time. Your responses are voluntary and will be confidential. All responses will be compiled together and analyzed as a group to address preceptor development and education.

\section{Demographics}

1. Where do you primarily practice within Duke Primary Care?

2. What is your age?

3. What is your race/ethnic identity?

African Asian Hispanic/Latino Indian American Indian Pacific Islander White/Caucasian Other

American/Black

Native American

4. What is your primary professional degree?

$\begin{array}{llll}\text { DO } & \text { MD } & \text { PA } & \text { Other } \\ & \bigcirc & 0 & \bigcirc\end{array}$

5. What is your primary area of practice?

Family Medicine Internal Medicine

Pediatrics

Urgent Care

6. How long have your been in practice?

\section{Past experience}

7. The following questions relate to your past experience as a preceptor.

8. Do you have a preference for the type of learner you would like to precept?

Yes No

9. In total how many years have you precepted learners (MD, NP, PA students or interns/residents)?

10. Have you precepted learners (MD, NP, PA students or interns/residents) in the last 6 months?

(NOTE: This should include ONLY continuity precepting, ie, more than 1 clinic session)

Yes No

11. If you have been a preceptor within the past two years, please tell us why you did so.

Figure I (Continued) 
12. Please estimate the number of learners you have precepted within the last 2 years.

Learner: Intern/Resident

Learner: Medical student

Learner: NP student

Learner: PA student

\section{Duke}

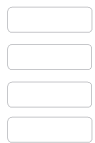

Non Duke

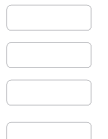

13. If you have precepted non-Duke learners, please include the sponsoring institution's name or affilitation.

\section{Looking forward}

14. How likely are you to precept a student in the next 6 months?

Likely Unlikely Undecided

15. How many months a year would you ideally precept IF given the appropriate incentives and time?

0 Months 1-2 months 3-4 months 5-6 months 7-10 months Every month

16. When considering potential barriers to your decision NOT to precept learners, please rank the top 5 reasons you would not precept a learner (1 MOST significant to 5 LEAST significant barriers).

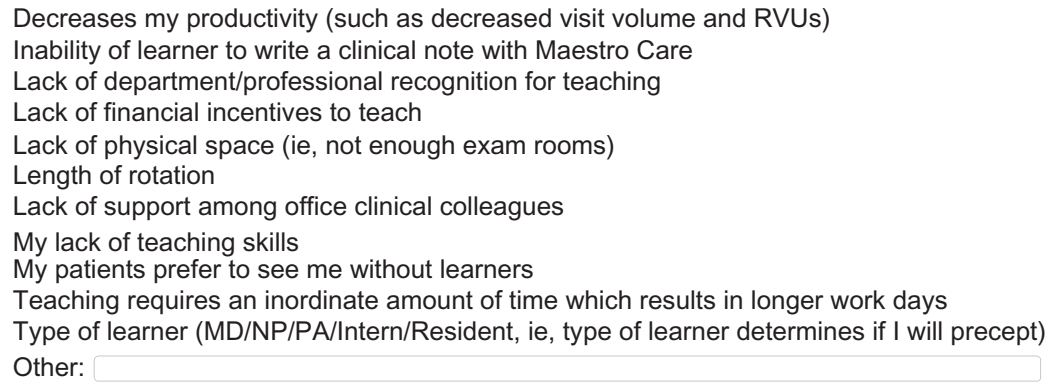

17. Considering reasons you would BEGIN or CONTINUE precepting learners, please rank your top 5 reasons to BEGIN or CONTINUE precepting (1 MOST IMPORTANT incentive to 5 LEAST IMPORTANT incentives):

\begin{tabular}{|l} 
Access to on-line training modules with free CME credits to provider \\
Adjusted appointment times to incorporate time for feedback to learner \\
Certificate or plaque of appreciation from Department \\
Enhanced employee benefit package \\
Faculty appointment with affiliated academic department \\
Monetary compensation \\
Parking passes for other Duke Medicine related obligations \\
Protected time to attend preceptor specific workshops or educational sessions \\
Reduced productivity expectations (ie, reduction in encounters, visit volume, RVUs) \\
Teaching gives me the opportunity to give something back to my profession \\
Other:
\end{tabular}

18. Do you feel precepting/teaching should be required?

Yes No

19. I need more education/training/faculty in effective precepting in the outpatient setting.

Yes No

20. Please add any additional comments regarding precepting within Duke Primary Care here (this section is optional)

Figure I Enlisting New Teachers In Clinical Environments (ENTICE) Survey; Duke Primary Care; Duke University, 2013.

Note: ENTICE Survey, Duke Primary Care, 2013.

Abbreviations: PA, physician assistant; NP, nurse practitioner; MD, Doctor of medicine; DO, Doctor of osteopathic medicine; CME, continuing medical education; RVU, relative value units.

space, length of learner rotation, and lack of teaching skills were also indicated as reasons to not teach.

When questioned about the future in terms of precepting, $65 \%$ ( $\mathrm{n}=58$ ) of respondents indicated that they were likely to precept a student within the next 6 months. Eleven percent were undecided. The majority of providers expressed that their ideal duration of teaching per year was between 1-4 months. However, $17 \%(\mathrm{n}=15)$ preferred to teach monthly.

The survey results showed that reduced productivity expectations were cited as the top reason respondents would begin to precept or continue to precept (Figure 2). An opportunity to "give back" to the profession and a desire for 
Table I Duke Primary Care ENTICE survey respondents' demographics by sex, age, race, professional degree, experience, area of practice

\begin{tabular}{|c|c|c|c|c|}
\hline & Male & Female & Total & $\%$ \\
\hline Total & 38 & 52 & 90 & 100 \\
\hline \multicolumn{5}{|l|}{ By age } \\
\hline$<25$ & 0 & I & I & 1.1 \\
\hline $25-30$ & 0 & 3 & 3 & 3.3 \\
\hline $31-35$ & 3 & 7 & 10 & 11.1 \\
\hline $36-40$ & 6 & 13 & 19 & 21.1 \\
\hline $41-49$ & 8 & 17 & 25 & 27.8 \\
\hline$\geq 50$ & 21 & II & 32 & 35.6 \\
\hline \multicolumn{5}{|l|}{ By Race/Ethnic identity } \\
\hline African American Black & 3 & 8 & II & 12.2 \\
\hline Asian & 0 & 8 & 8 & 8.9 \\
\hline Hispanic/Latino & 0 & 0 & 0 & 0 \\
\hline Indian & I & 3 & 4 & 4.4 \\
\hline American Indian/Native American & 0 & 0 & 0 & 0 \\
\hline Pacific Islander & 0 & I & I & 1.1 \\
\hline White/Caucasian & 31 & 33 & 64 & 71.1 \\
\hline Other & I & I & 2 & 2.2 \\
\hline \multicolumn{5}{|l|}{ By professional degree } \\
\hline Doctor of osteopathic medicine & I & I & 2 & 2.2 \\
\hline Doctor of medicine & 31 & 35 & 66 & 73.3 \\
\hline Nurse practitioner & 2 & 6 & 8 & 8.9 \\
\hline Physician assistant & 4 & 10 & 14 & 15.6 \\
\hline Other & 0 & 0 & 0 & 0 \\
\hline \multicolumn{5}{|l|}{ By years in practice } \\
\hline$<2$ years & 2 & 6 & 8 & 8.9 \\
\hline $3-5$ years & 7 & 12 & 19 & 21.1 \\
\hline $6-10$ years & 3 & 9 & 12 & 13.3 \\
\hline $11-15$ years & 7 & II & 18 & $20 . c$ \\
\hline$>15$ years & 19 & 14 & 33 & 36.7 \\
\hline \multicolumn{5}{|l|}{ By primary area of practice } \\
\hline Family Medicine & 24 & 28 & 52 & 57.8 \\
\hline Internal Medicine & 7 & 13 & 20 & 22.2 \\
\hline Pediatrics & 3 & I & 4 & 4.4 \\
\hline Urgent Care & 4 & 10 & 14 & 15.6 \\
\hline
\end{tabular}

Note: Enlisting New Teachers in Clinical Environments (ENTICE) Survey, Duke Primary Care, 2013.

adjustment in appointment scheduling were also important factors cited. A desire for enhanced monetary compensation and protected time to attend faculty development sessions were additionally desired. Also, there was interest in online training modules with free continuing medical education (CME) credits. A faculty appointment was also of interest to some providers.

The most commonly cited disincentive for a provider to consider not teaching in the future was the anticipated reduction in productivity (Figure 2). Time constraints, a lack of financial incentive, and compliance concerns relating to note writing were additional issues that were cited. There was also a perception that patients did not wish to be seen
Table 2 Duke Primary Care ENTICE survey respondents' reasons for teaching during the past 2 years

\begin{tabular}{ll}
\hline & $\begin{array}{l}\text { Number of } \\
\text { Comments }\end{array}$ \\
\hline $\begin{array}{l}\text { Enjoy teaching, personal interaction } \\
\text { and helping students learn }\end{array}$ & 20 \\
Required to teach/student assigned & 10 \\
Opportunity to learn from students & 8 \\
Committed to the future of the specialty & 7 \\
Prior experience as a preceptor & 4 \\
Personally asked by department or learner & 3 \\
Responsibility to give back to the profession & 3 \\
Willingness to pay preceptors & 3 \\
Duke needs preceptors & 2 \\
Pediatric residents from Duke rotate & । \\
through practice & I \\
Frequently have learners in clinic & I \\
Able to obtain CME credits & \\
Responsibility/citizenship & \\
Schedule was flexible & \\
\hline Note: Enlisting New Teachers in Clinical Environments (ENTICE) Survey, Duke \\
Primary Care, 20 3 . \\
Abbreviation: CME, continuing medical education.
\end{tabular}

\section{Discussion}

This survey represents a rare opportunity to study a change of focus and emphasis for a cohort of busy clinicians who were mostly new to teaching but not new to clinical prac-

Table 3 Duke Primary Care ENTICE survey respondents' reasons for not teaching during the past 2 years

\begin{tabular}{ll}
\hline & $\begin{array}{l}\text { Number of } \\
\text { Comments }\end{array}$ \\
\hline Lack of time & 10 \\
Increased demands/RVU expectations & 9 \\
No opportunity & 7 \\
Current reimbursement model is a disincentive & 5 \\
to teaching & \\
Not interested/not a good teacher & 3 \\
EMR transition & 2 \\
Worked outside academia prior to this job & $\mathrm{I}$ \\
FTE and rotate sites & $\mathrm{I}$ \\
New to practice; not ready for students & $\mathrm{I}$ \\
\hline Note: Enlisting New Teachers in Clinical Environments (ENTICE) Survey, Duke \\
Primary Care, 2013. \\
$\begin{array}{l}\text { Abbreviations: RVU, relative value units; EMR, electronic medical records; FTE, } \\
\text { full-time equivalent. }\end{array}$
\end{tabular}


Top reasons ENTICE survey respondents gave to begin

or continue to precept learners

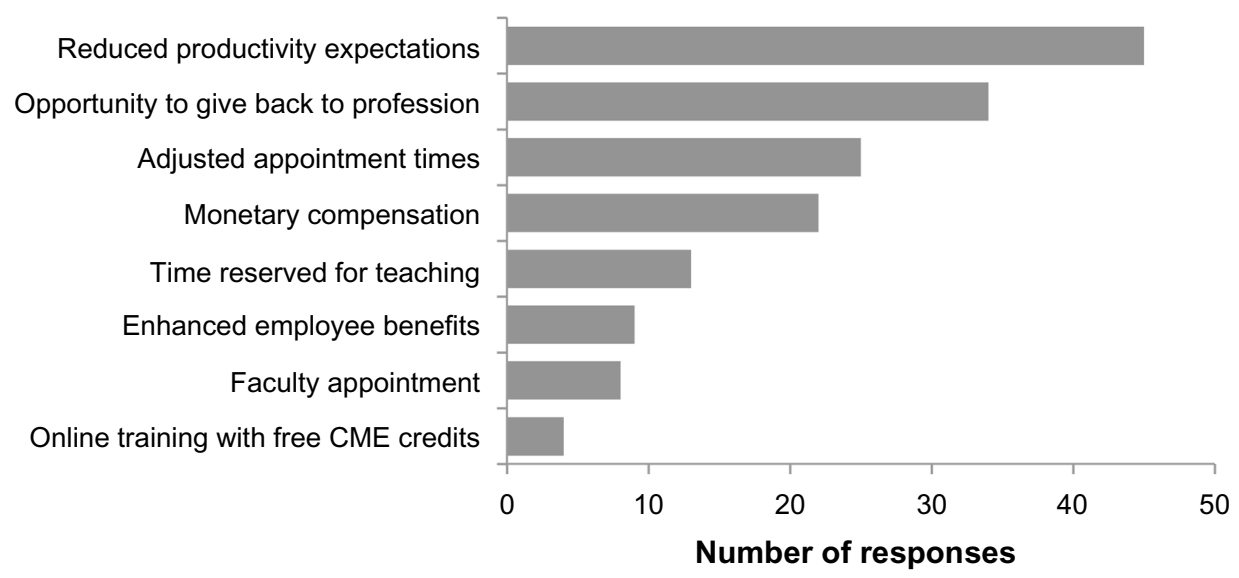

Top reasons ENTICE survey respondents gave not to precept learners in the future

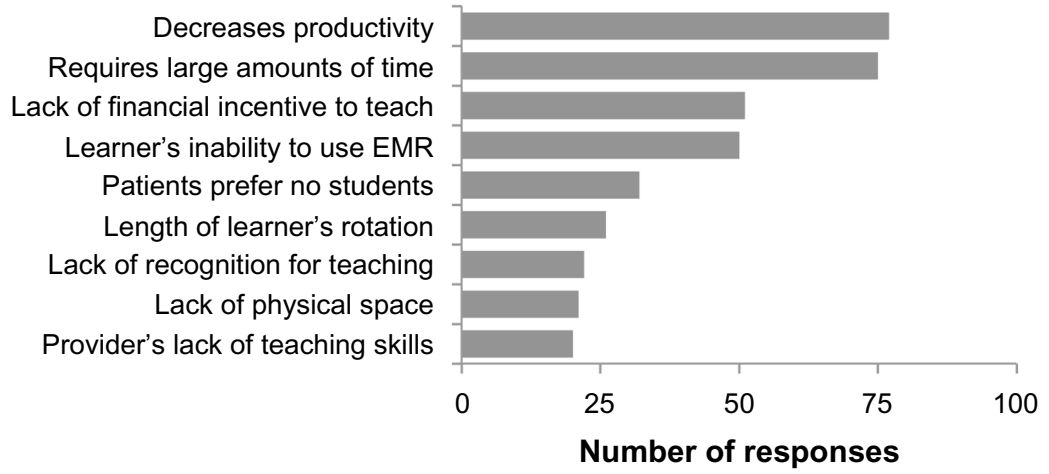

Figure 2 Top reasons Duke Primary Care Enlisting New Teachers in Clinical Environments (ENTICE) survey respondents gave to begin/continue to precept learners or not to precept learners in the future. ENTICE Survey, Duke Primary Care, 2013.

Abbreviations: CME, continuing medical education; EMR, electronic medical records.

tice. Close to $60 \%(n=51)$ of the providers had practiced for 11 years or more but most were inexperienced teachers. Slightly more than one-half had been teaching for 5 years or less.

Provider perceptions are critical to understand as new teaching preceptors are sought out. The results and data align with data from previous studies in that time pressures and productivity demands transcend programs, learners, and institutions. ${ }^{15,16}$ Latessa et al's recent review from August 2013 provides an excellent review of the concerns of current community providers also from the state of North Carolina. ${ }^{17}$ Our particular study adds to the literature by detailing an additional inducement that may encourage new inexperienced providers to begin to precept. Many preceptors teach because of the intrinsic benefits, which outweigh extrinsic rewards such as higher pay. Interestingly, new clinicians considering adoption of a teaching role did so because of a desire for a reduction in workload with subsequently reduced productivity expectations. Unfortunately, this incentive identified more of a hypothetical request than a current specific policy at our institution. Nonetheless, the identification of such a strong desire on the part of clinicians represents a valuable opportunity for future work expectation adjustments.

These desired rewards differ somewhat from previously detailed incentives provided to clinician educators. In 2001, Ulltian et al detailed the importance of faculty development and appreciation as inducements to teach, ${ }^{18}$ which was replicated in the study of community-based preceptors studied by Ryan et al, though that study involved a significantly lower overall response rate and involved only pediatricians. ${ }^{19}$ Interestingly, Peters et al looked at some of the specific effects of stipend awards to faculty and found that few ranked this as their major reason for continuing to teach. ${ }^{20}$ This correlates 
with findings from two other studies that deemphasized the importance of payment for teaching. . $^{21,22}$

Additionally, this finding was also found in studies from outside of the United States. Scot and Sazegar's study from British Columbia in 2006 detailed how remuneration was one of the "least important" reasons for teaching. ${ }^{22}$ More recently, the study by Pichlhofer et al, which involved medical students in general practice in Austria, found that again, payment for teaching was a low priority and not a motivational factor. ${ }^{23}$ These studies contrasted slightly with the larger review of 35 articles that was carried out by Campbell and McAllister in 2012. Many of these studies originated in Australia. In this review, it was determined that lack of financial reward did have a negative influence on providers, though this was less important than lack of access to faculty development. ${ }^{24}$

ENTICE yielded important insight into the priorities and goals of providers who were experienced clinicians but not necessarily experienced teachers. The majority were willing to teach for up to one-third of the year, but few wanted to teach for longer periods. It follows that determination and delivery of desired incentives may possibly lead to longer durations of a teaching commitment by potential preceptors. Faculty development was viewed ambivalently, perhaps correlating with overestimation of skill sets and desire not to attend meetings in off hours.

There were limitations to this project. We obtained a response rate of $50 \%(n=90)$ representing a wide variety of primary care providers from 33 clinics; however, it is likely that the group of providers who failed to respond to the survey might be less supportive and less engaged in teaching. Our data are preliminary, and it would be helpful to collect further feedback and information relating to teaching after proposed policy changes have been extant for several years. Future research could involve a larger sample size, including medical and surgical specialties and not just primary care providers, and a longer period of study would prove to be beneficial as well. Additional focus could also be placed upon the concurrent teaching of health professional students by faculty outside of one's own area of focus (eg, the precepting of medical students by physician assistant or nurse practitioner faculty). A final area for proposed study would be to look at the process of what happens when noneducators start to teach. Is their teaching valuable and effective, or perhaps, maybe instruction by providers other than clinician educators is substandard and/or insufficient in quality and/or quantity?
In summary, we found clinicians new to teaching in the outpatient setting desire adjustments in work productivity. This incentive is first and foremost, though a number of other incentives exist that may be used to induce and retain primary care clinical faculty for this role. A very recent discussion about ways to enhance value to relative value units by Stecker and Schroeder, is quite germane to this process, and their work could lead to enhanced and/or adjusted relative value units allocation for items such as team-based care and supervision of clinical activities such as teaching. ${ }^{25}$

Precepting learners is a productive and time-consuming effort that significantly contributes to an institution's educational mission, and this process ought not to be devalued. Simply adding on further work expectations and commitments to already time-challenged primary care providers will not likely result in long-term increases in clinicians who can care for patients and teach at the same time.

\section{Acknowledgments}

The authors would like to thank John B Anderson, MD, MPH, Pamela B Edwards, EdD, MSN, RN-BC, CNE, and Barbara $\mathrm{S}$ Turner, $\mathrm{PhD}, \mathrm{RN}, \mathrm{FAAN}$ for their guidance and support in developing the survey.

\section{Disclosure}

The authors report no conflicts of interest in this work.

\section{References}

1. Petterson SM, Liaw WR, Phillips RL, Rabin DL, Meyers DS, Bazemore AW. Projecting US primary care physician workforce needs: 2010-2015. Ann Fam Med. 2012;10(6):503-509.

2. Ogur B, Hirsh D, Krupat E, Bor D. The Harvard Medical School-Cambridge integrated clerkship: an innovative model of clinical education. Acad Med. 2007;82(4):397-404.

3. Dill MJ, Salsburg ES. The complexities of physician supply and demand: projections through 2025. Center for Workforce Studies, Association of American Medical Colleges. 2008:65-67.

4. Association of American Medical Colleges Center for Workforce Studies. Results of the 2012 Medical School Enrollment Survey. Washington, DC; 2013. Available from: https://members.aamc.org/ eweb/upload/12-237\%20EnrollmSurvey2013.pdf. Accessed November 9, 2013.

5. Georgetown Center on Education and the Workforce. Healthcare Report: Jun 2012. Available from: http://cew.georgetown.edu/healthcare/. Accessed November 1, 2013.

6. Glicken AD, Miller AA. Physicians assistants: from pipeline to practice. Acad Med. 2013;88(12):1883-1889.

7. Glicken A, Lane S. Results of the PAEA 2006 survey of PA program expansion plans. J Physician Assist Educ. 2007;18(1):48-53.

8. Lyon DE, Peach J. Primary care provider's views of precepting nurse practitioner students. J Am Acad Nurse Pract. 2001;13(5): 237-240.

9. Alguire PC, DeWitt DE, Pinskey LE, Ferenchick GS. Teaching in Your Office: A Guide to Instructing Medical Students and Residents. Philadelphia, PA: American College of Physicians; 2008. 
10. Gray BH, Stockley K, Zucherman S. American primary care physicians' decisions to leave their practice: evidence from the 2009 commonwealth fund survey of primary care doctors. J Prim Care Community Health. 2012;3(3):187-194.

11. Wiseman RF. Survey of advanced practice student clinical preceptors J Nurs Educ. 2013;52(5):253-258.

12. Brooks M, Niederhauser V. Preceptor expectations and issues with nurse practitioner clinical rotations. J Am Acad Nurse Prac. 2010;22(11): 573-579.

13. Campbell SH, Hawkins JW. Preceptor rewards: how to say thanks for mentoring the next generation of nurse practitioners. J Am Acad Nurse Prac. 2007;19(1):24-29.

14. Gonzalez-Calaso R, Moloney-Johns A, Sivahop J. To teach or not to teach: 2011 national survey of physician assistants and preceptor experiences. J Physician Assist Educ. 2013;24(2):12-20.

15. Latessa R, Beaty N, Colvin G, Landis S, Janes C. Family medicine community preceptors: different from other physician specialties? Fam Med. 2008;40(2):96-101.

16. Latessa R, Beaty N, Landis S, Colvin G, Janes C. The satisfaction, motivation, and future of community preceptors: the North Carolina experience. Acad Med. 2007;82(7):698-703.

17. Latessa R, Colvin G, Beaty N, Steiner BD, Pathman DE. Satisfaction, motivation, and future of community preceptors: what are the current trends? Acad Med. 2013;88(8):1164-1170.
18. Ulltian JA, Shore WB, First LR. What did we learn about the impact on community-based faculty? Recommendations for recruitment, retention, and rewards. Acad Med. 2001;76(Suppl 4):S78-S85.

19. Ryan MS, Vanderbilt AA, Madden MA. Benefits and barriers among volunteer teaching faculty: comparison between those who precept and those who do not in the core pediatrics clerkship. Med Educ Online. 2013;18:1-7.

20. Peters AS, Schnaidt KN, Zivin K, Rifas-Shiman SL, Katz HP. How important is money as a reward for teaching? Acad Med. 2009;84(1): 42-46.

21. Kumar A, Kallen D, Mathew T. Volunteer faculty: what rewards or incentives do they prefer? Teach Learn Med. 2002;14(2):119-123.

22. Scott I, Sazegar P. Why community physicians teach students (or not): barriers and opportunities for preceptor recruitment. Med Teach. 2006;28(6):563-565.

23. Pichlhöfer O, Tönies H, Spiegel W, Wilhelm-Mitteräcker A, Maier M. Patient and preceptor attitudes towards teaching medical students in General Practice. BMC Med Educ. 2013;13:83.

24. Campbell N, McAllister L, Eley D. The influence of motivation in recruitment and retention of rural and remote allied health professionals: a literature review. Rural Remote Health. 2012;12:1900.

25. Stecker EC, Schroeder SA. Adding value to relative-value units. $N$ Engl J Med. 2013;369(23):2176-2179.
Advances in Medical Education and Practice

\section{Publish your work in this journal}

Advances in Medical Education and Practice is an international, peerreviewed, open access journal that aims to present and publish research on Medical Education covering medical, dental, nursing and allied health care professional education. The journal covers undergraduate education, postgraduate training and continuing medical education

\section{Dovepress}

including emerging trends and innovative models linking education, research, and health care services. The manuscript management system is completely online and includes a very quick and fair peer-review system. Visit http://www.dovepress.com/testimonials.php to read real quotes from published authors.

Submit your manuscript here: http://www.dovepress.com/advances-in-medical-education-and-practice-journal 